\title{
Effects of fluticasone propionate on inflammatory cells in CO PD: an ultrastructural examination of endobronchial biopsy tissue
}

\author{
M J Gizycki, K L Hattotuwa, N Barnes, P K J effery
}

Thorax 2002;57:799-803

See end of article for authors' affiliations

Correspondence to:

Professor P K Jeffery, Lung

Pathology Unit, Royal

Brompton Hospital, London

SW 3 6N P, UK;

p.jeffery@ic.ac.uk

Revised version received

12 June 2002

Accepted for publication

17 June 2002

inflammation in asthma

Background: Inhaled corticosteroids (ICS) markedly reduce bronchial mucosal inflammation in asthma but whether they have an anti-inflammatory effect in airway tissue in chronic obstructive pulmonary disease (CO PD) is unknown.

Methods: A study of endobronchial biopsy samples was conducted as part of a double blind, placebo controlled, randomised trial of parallel design. Patients had mild to moderately severe CO PD (FEV $25-80 \%$ of predicted) and were given 3 months trea tment with IC S, flutica sone propionate (FP; $500 \mu \mathrm{gg}$ twice daily, $n=14)$ or placebo $(n=10)$. Biopsy tissue taken at baseline and after treatment was examined by transmission electron microscopy to count the numbers of all ultrastructurally distinct inflammatory cells.

Results: Compared with their baseline values, FP resulted in a significant decrease (on average $65 \%$ ) in the numbers of mucosal mast cells (median 7.8 (range $1-33$ ) v $2.8(1-14), p<0.05$ ). The reductive effect of FP held true when the post-treatment values of the placebo and FP groups were compared: 8.8 $(1-24) \vee 2.8(1-14)(p<0.05)$. Unexpectedly, there were significantly more neutrophils in the FP than in the placebo group: $4.0(0-23) \vee 1.7(0-8)$, respectively $(p<0.05)$. There were no alterations to other cell types including mononuclear cells. Symptoms markedly improved in the patients treated with FP for 3 months.

Conclusion: Fluticasone propionate given for 3 months to patients with CO PD has selective effects on the inflammatory cells in the bronchial mucosa: the reduction in mast cell numbers may account for the improvement in symptoms over this time.

C hronic bronchitis (CB) and chronic obstructive pulmonary disease (COPD) are common disorders with high morbidity and mortality. CB is characterised by chronic cough and expectoration of phlegm, COPD by largely irreversible and progressive airflow obstruction. ${ }^{1-3}$ Analyses of bronchial biopsies, resected lung tissue, and induced sputum have shown that there is inflammation, even in the stable phase of COPD. Based on the effectiveness of inhaled corticosteroids (ICS) as anti-inflammatory agents in the treatment of asthma, the presence of mucosal inflammation in COPD is one rationale for their use in this condition but there have been no biopsy based studies to validate this approach. M oreover, the response to ICS in COPD may be different from that in asthma as the predominant inflammatory cell infiltrates in both these conditions are distinct. Eosinophils, mast cells, and CD4+ T lymphocytes are the principal inflammatory cells in mild to moderate asthma, ${ }^{4}$ whereas the predominant pattern of inflammation in stable COPD consists of CD8+ T lymphocytes, CD68+ macrophages and, to lesser extent, neutrophils in both conducting airways and lung parenchyma. ${ }^{5-8}$ Smoking, a major cause of CB and COPD, is also associated with an increase in the numbers of mast cells in the mucosa of both large and small airways. ${ }^{910}$ The effect of corticosteroids on these cell types in COPD has not been determined.

While the EUROSCOP and ISOLDE clinical trials have shown no beneficial effect of ICS on the long term rate of lung function decline in COPD, they have shown significant improvement in forced expiratory volume in 1 second $\left(F V_{1}\right)$ over the first 3-6 months of treatment. ${ }^{11}{ }^{12}$ In the relatively more severe group of patients in the ISOLDE trial, fluticasone propionate (FP) also reduced the frequency of exacerbations and ICS were perceived to be of clinical benefit, at least in some individuals. The mechanisms responsible for these ben- eficial effects and the reason why some patients should ben efit are unclear. The characteristics of the patients recruited here, the study design, and dose of ICS were similar to those of the ISOLDE study. Based on the results of the ISOLDE study, we hypothesised that ICS would reduce inflammatory cells, but only those associated with the short term improvement in lung function and not those thought to be associated with the long term accelerated decline of COPD.

In the present study, the first of its kind, we report the results of applying transmission electron microscopy (TEM) to the examination of endobronchial biopsy specimens in detecting treatment related changes to the overall inflammatory infiltrate in COPD. The results of immunostaining viewed by light microscopy of complementary biopsy specimens obtained from the same patients are reported elsewhere. ${ }^{13}$ TEM has the advantage that all morphologically distinct inflammatory cell phenotypes present in a single tissue section can be identified during one viewing. All granulated cell types including mast cells, eosinophils, and neutrophils are particularly well recognised and distinguished from each other by the distinct ultrastructure of their intracellular granules. M oreover, cell degranulation and apoptotic cells can be readily identified. In contrast, conventional immunostaining of bronchial tissue viewed by light microscopy is a quite different technique and identifies only one immunohistochemically distinct cell phenotype at a time. However, immunostaining of distinct cell surface associated epitopes has the advantage of distinguishing lymphocyte subsets and other mononuclear cells that is difficult with conventional TEM. The results of these two distinct studies of the same patients carried out by different researchers have therefore been published separately. 
Table 1 Mean (SD) demographic characteristics of study patients

\begin{tabular}{lll}
\hline Characteristics & Placebo & Fluticasone \\
\hline Male/ female & $9 / 1$ & $13 / 1$ \\
Age & $65.5(7)$ & $65.3(6)$ \\
$\mathrm{FEV}_{1}(\mathrm{I})$ & $1.46(0.4)$ & $1.44(0.4)$ \\
$\mathrm{FEV}_{1}$ (\% predicted) & $49.7(13.4)$ & $50.3(12.7)$ \\
$\mathrm{VC}$ (litres) & $3.5(0.9)$ & $3.7(0.7)$ \\
$\mathrm{FEV}_{1} / \mathrm{VC}(\%)$ & $53.6(9.9)$ & $49.9(14.4)$ \\
$\mathrm{FEV}_{25-75}$ & $0.54(0.2)$ & $0.52(0.3)$ \\
Reversibility (\%) & $7.6(5.8)$ & $6.8(5.8)$ \\
Kco $\left(\%\right.$ predicted) $_{\text {Pack years }}$ & $55.0(4.5)$ & $52.0(5.1)$ \\
Cigarettes/ day & $63.3(36)$ & $57.6(36)$ \\
\hline
\end{tabular}

$\mathrm{FEV}_{1}=$ forced expiratory volume in 1 second; $\mathrm{VC}=$ vital capacity; $\mathrm{KCO}=$ carbon monoxide transfer coefficient.

\section{METHODS}

\section{Patients}

Patients were chosen who had clinical characteristics that closely resembled those in the ISOLDE study. ${ }^{12}$ They were recruited from chest clinics at the London Chest Hospital and by advertisement. The study conformed to the Declaration of Helsinki and ethical approval was obtained from the East London City Health Authority.

Patients eligible for study were aged $40-75$ years, were current or ex-smokers with more than 20 pack years of smoking, non-atopic, and with an FEV $25-80 \%$ of predicted which improved less than $15 \%$ following $400 \mu$ inhaled sal butamol. Of the 37 patients who were recruited, four had mild airflow obstruction ( $F E V_{1} 60-80 \%$ of predicted), 20 had moderate obstruction ( $40-60 \%$ of predicted), and 13 had severe airflow obstruction ( $<40 \%$ of predicted). Patients with severe concurrent medical problems, psychological impairment, those on immunosuppressive treatment, or with a chest infection during the 8 weeks before the study were excluded. Patients who were al ready on inhaled steroids had the drug withdrawn and had to be stable for at least 8 weeks before the first biopsy sample was taken. All reliever medications (inhaled $\beta_{2}$ agonist, anticholinergic agents, and theophylline) were continued as previously administered and required. All patients underwent a full physical examination, baseline pulmonary function testing (spirometry, flow-volume loop, and transfer factor), full blood count, assessment of electrolytes, liver function tests, total IgE, and RAST test to house dust mite, mixed feathers, grass pollen, cat, and dog fur.

The demographic characteristics of the patients are summarised in table 1.

\section{Trial design}

The recruited subjects had a run in period of 8 weeks to ensure they were stable before the first bronchoscopic examination. Two weeks after the baseline biopsy specimen was taken, patients were randomised to receive either placebo or $500 \mu \mathrm{g}$ FP twice daily via an Accuhaler for a period of 3 months. The dose of drug chosen was similar to that used in the ISOLDE trial. The subjects were required to keep a twice daily diary of peak flows and symptoms. At each monthly visit they had tests of pulmonary function and assessment of symptoms such as cough, sputum (purulence or volume), breathlessness, wheeze, exercise capacity, reliever medication use times, and general well being.

A second biopsy specimen was taken within 2 weeks of completing the treatment. The patients were then reviewed in clinic and followed up for a further month to ensure no clinical deterioration occurred since stopping the inhaled treatment. Following this they received a trial of $30 \mathrm{mg}$ oral prednisolone for 2 weeks to determine the maximal degree of airflow obstruction reversibility; patients were considered as responders if their $\mathrm{FEV}_{1}$ improved by more than $15 \%$ and by at least $200 \mathrm{ml}$ in absolute terms from their baseline value.

Bronchoscopic examination and processing of biopsy samples

Patients had their bronchoscopic examination as a hospital day case, applying the standards set by the American Thoracic Society. Following an overnight fast they were admitted to the day case unit and baseline observations were taken. All subjects then received $2.5 \mathrm{mg}$ nebulised salbutamol and $600 \mu \mathrm{g}$ atropine intramuscularly as premedication. During the bronchoscopic examination they were monitored by pulse oximetry, received lignocaine spray to the oropharynx, and 2.5-5 mg midazolam was given intravenously; $4 \%$ lignocaine was instilled via the bronchoscope to the vocal cords and $2 \%$ lignocaine was used intrabronchially. Bronchial biopsy specimens were obtained from the carinae of the second order bronchi of the right middle and lower lobes using a Pentax FB18x and Pentax x1718A cup forceps. Following bronchoscopic examination the patients were observed and discharged home with a follow up during the following 2 weeks. Two biopsy specimens per patient were prepared for examination by transmission electron microscopy (TEM) using the methods previously described. ${ }^{14}$ Areas of the biopsy specimen with intact surface epithelium were selected for further examination and quantification by TEM carried out at a total magnification of $\times 2000(\mathrm{H}-7000$, Hitachi, J apan).

\section{Quantification}

Inflammatory cells were counted in a subepithelial zone in the entire TEM section and expressed per $0.1 \mathrm{~mm}^{2}$ of tissue, excluding areas with bronchial smooth muscle, mucus secreting glands, and oedema. The entire section was photographed at low magnification and the excluded areas were subtracted from the total area using image analysis (NIH Image 1.61, California, US). The numbers of lymphomononuclear cells, mast cells, neutrophils, eosinophils, plasma cells, macrophages, and fibroblasts were counted: a group of cells difficult to classify was included. The criteria for ultrastructural identification of morphologically distinct cell types were those described in our previously published papers. ${ }^{14}{ }^{15}$ The frequency of clusters of free eosinophil granules (Cfegs) as a marker of eosinophil cytolysis was also determined. ${ }^{14}{ }^{16}$

\section{Statistical analysis}

Statistical analyses were performed using computer software (Statview 5.0, Abacus Concepts, California). The coefficient of variation for the error of repeat measurement for each cell type was less than $5 \%$. As the data were not all distributed normally, the Wilcoxon signed rank test was applied to examine differences between paired data and the $M$ ann-Whitney $U$ test for between treatment comparisons was applied to the post-treatment values. The Spearman rank correlation coefficient was used to evaluate associations between histological and clinical variables. Probability ( $p$ ) values of less than 0.05 were accepted as statistically significant.

\section{RESULTS}

Patient characteristics

Of the 37 patients initially enrolled into the study, 31 completed the trial. One patient withdrew for personal reasons and one patient died of a cause unrelated to the study. Necroscopic examination gave the cause of death as respiratory failure resulting from severe emphysema and pulmonary hypertension. Four further patients had to withdraw because of exacerbations of COPD. M ost exacerbations requiring oral prednisolone occurred in the placebo group ( $p=0.02 \mathrm{com}$ pared with FP group). There was insufficient biopsy material to analyse on at least one occasion in seven patients, so they were excluded from ultrastructural analysis. 
Table 2 Median (range) bronchial inflammatory cells expressed per $0.1 \mathrm{~mm}^{2}$ tissue

\begin{tabular}{llllll}
\hline & \multicolumn{2}{l}{ Placebo $(n=10)$} & & \multicolumn{2}{l}{ Fluticasone $(n=14)$} \\
\cline { 2 - 3 } \cline { 5 - 6 } & $\begin{array}{l}\text { Before } \\
\text { treatment }\end{array}$ & $\begin{array}{l}\text { After } \\
\text { treatment }\end{array}$ & & $\begin{array}{l}\text { Before } \\
\text { treatment }\end{array}$ & $\begin{array}{l}\text { After } \\
\text { treatment }\end{array}$ \\
\hline Fibroblasts & $36.0(6-74)$ & $30.1(9-69)$ & & $23.6(12-64)$ & $20.0(5-56)$ \\
Lymphomononuclear cells & $35(10-145)$ & $30.1(0-182)$ & & $24.3(11-196)$ & $30.2(0-179)$ \\
M ast cells & $10.8(4-23)$ & $8.8(1-24)$ & & $7.8(1-33)$ & $2.8(1-14)^{*}$ \\
Eosinophil (total) & $1.8(0-11)$ & $0.0(0-10)$ & & $1.1(0-75)$ & $1.2(0-30)$ \\
$\quad$ Eosinophil dense & $0.7(0-8)$ & $0.0(0-7)$ & & $0.8(0-52)$ & $0.9(0-27)$ \\
$\quad$ Eosinophil clear & $0.0(0-3)$ & $0.0(0-8)$ & & $0.0(0-23)$ & $0.0(0-2)$ \\
Cfegs & $1.5(0-12)$ & $0.0(0-3.6)$ & & $0.0(0-38)$ & $0.0(0-5)$ \\
N eutrophils & $3.0(0-10)$ & $1.7(0-8)$ & & $3.2(1-12)$ & $4.0(0-23)^{*}$ \\
M acrophages & $8.8(3-20)$ & $9.3(1-20)$ & & $7.0(3-31)$ & $10.1(0-20)$ \\
Plasma cells & $3.9(0-37)$ & $3.6(0-60)$ & & $5.0(0-66)$ & $1.8(0-26)$ \\
DTC & $17(5-37)$ & $15.1(5-33)$ & & $15.4(5-66)$ & $15.9(3-49)$ \\
\hline
\end{tabular}

Eosinophil dense=electron dense secretory granules; eosinophil clear=electron lucent secretory granules; $C$ fegs=clusters of free eosinophils granules; DTC =difficult to classify. $* p<0.05$ FP $v$ placebo.

Patients were well matched for age, smoking history, and lung function (table 1).

\section{Lung function}

Data from 31 patients were available for analysis of lung function and symptoms and the results are published elsewhere. There were no significant differences in the lung function tests between the FP and placebo groups at the end of the treatment period. However, there were improvements in the scores for cough $(p<0.05)$, sputum $(p<0.05)$, and decreased use of reliever medication $(p<0.05)$ after 3 months of FP compared with placebo. No significant differences were observed in breathlessness, wheezing, exercise tolerance, or general well being.

Of the 31 patients who completed the trial, 29 underwent an oral corticosteroid trial of $30 \mathrm{mg}$ prednisolone and two patients were considered as responders. One of them was in the placebo group and reported worsening of symptoms during the trial period. The responder in the FP group reported improvement in all categories of symptoms during the trial. The examination of biopsy specimens from these subjects showed that their results did not significantly influence the between group differences. Placebo treatment had no effect on any of the clinical parameters.
Biopsy results

Adequate tissue was obtained in the 24 patients who completed the study. Most biopsy specimens had intact epithelium with a reticular basement membrane which appeared to be of normal thickness. Among the granulated cells, mast cells were most numerous at the baseline and were found both beneath and within the epithelium; those in the epithelium were often degranulated. Eosinophils occurred infrequently and were usually not degranulated; Cfegs, as an indicator of eosinophil lysis, were also sparse. In contrast to neutrophils, no apoptotic eosinophils were identified. M acrophages identified by their phagolysosomes were found occasionally in the process of engulfing apoptotic neutrophils. The numbers of ultrastructurally distinct cell types are shown in table 2.

Compared with their respective baseline values, FP treatment had no significant effects on the total number of inflammatory cells, lymphomononucl ear cells, or macrophages in the airway mucosa. However, treatment with FP resulted in a $65 \%$ reduction in the numbers of mucosal mast cells $(p<0.05)$, and this reduction was also significant when compared with the post-treatment values in the placebo group ( $p<0.05$, fig 1 ).

Comparison of post-treatment values showed that the FP group had statistically more neutrophils than the placebo
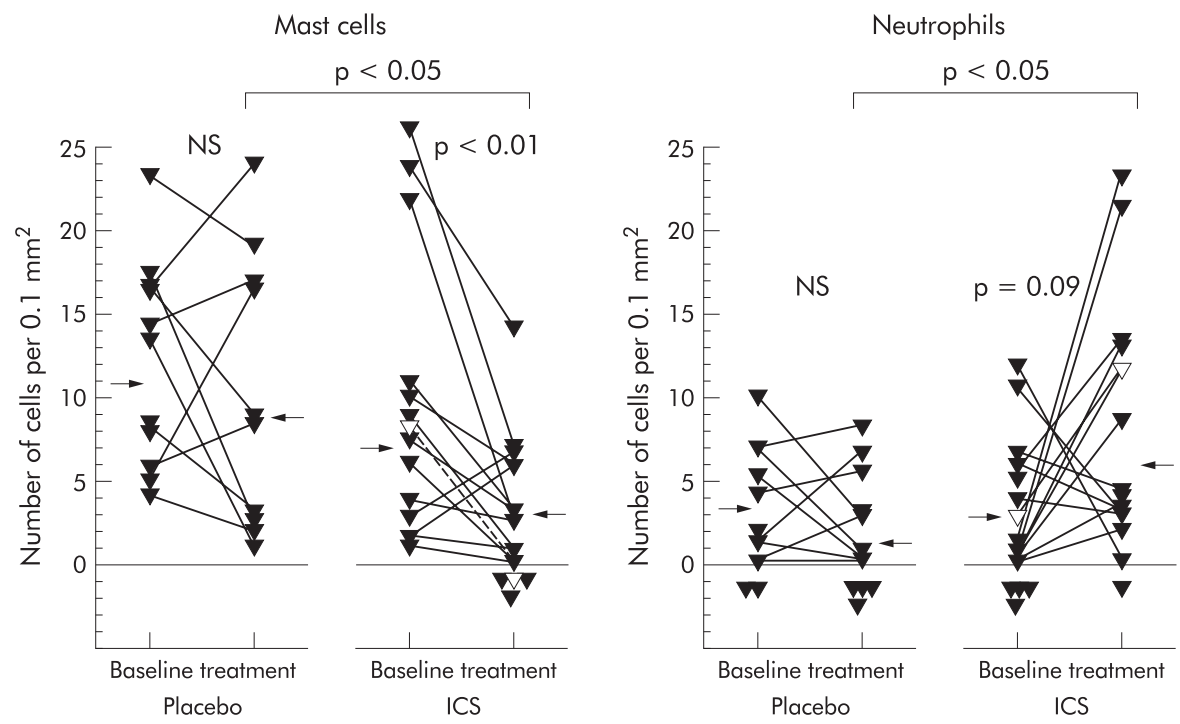

Figure 1 Effect of treatment with fluticasone propionate (FP) on bronchial mast cells and neutrophils. A reduction in mast cells of approximately $65 \%$ compared with baseline values was seen. N eutrophils increased by a mean of $50 \%$. 0 pen triangles represent patients who responded positively to the prednisolone trial. Arrows indicate the median values. 
group ( $p<0.05$, fig 1 ). However, this relative increase in the FP group failed to reach significance compared with the respective within group baseline values $(p=0.09)$. FP did not alter the sparse number of tissue eosinophils. The highest number of eosinophils was observed at baseline in the group subsequently treated with $\mathrm{FP}$, and this was in a patient who responded positively to the course of oral prednisolone following the study. There was no effect of FP treatment on the subsets of eosinophils with "clear" or "dense" granules or on the numbers of Cfegs as indices of eosinophil degranulation. Placebo had no significant effect on any parameter. There was no significant correlation between the results of lung function tests and inflammatory cells at baseline.

\section{DISCUSSION}

The current use and efficacy of ICS in the treatment of COPD has been debated. ${ }^{17-20}$ To our knowledge this is the first published study of the anti-inflammatory potential of ICS on airway tissues in COPD. Three months of treatment with FP $(500 \mu \mathrm{g} \mathrm{bd})$ did not significantly alter the numbers of bronchial mononuclear cells, which are considered to be key cells contributing to lung tissue destruction in COPD. ${ }^{51} \mathrm{How}-$ ever, FP significantly reduced the numbers of ultrastructurally distinct mucosal mast cells. This effect of ICS on mast cells in COPD has subsequently been confirmed in a distinct immunohistochemical study of complementary biopsy specimens obtained from the same patients in which mast cell tryptase positive cells showed a $25 \%$ reduction in response to treatment with ICS. ${ }^{13}$

The immunohistological study also showed that FP did not affect the numbers of CD8+ and CD68+ cells, a result compatible with the lack of effect shown by TEM on mononuclear cells. The differences in the immunohistological and ultrastructural techniques indicate one major advantage of the electron microscopic approach. TEM provides a method for quantifying a number of morphologically distinct inflammatory cell types in one and the same section. In this way the TEM technique highlighted the reduction in mast cells in response to ICS, an effect that otherwise might have been missed by analyses of only the primary end points of our immunohistological study.

The role of mast cells in the pathogenesis of COPD is unclear. Mast cells have been reported to increase in both the mucosa and submucosal glands in bronchial biopsies of smokers with chronic bronchitis. ${ }^{22}$ In lungs resected from smokers with cancer there is an increased number of mast cells in the epithelium of small airways ${ }^{9}$ which is greater in smokers with airflow obstruction (COPD) ${ }^{10}$ suggesting a role for mast cells in airflow limitation. In the present study the reduction in the number of mast cells was accompanied by a significant improvement in symptoms such as cough and sputum and the patients given FP experienced fewer exacerbations. However, breathlessness, exercise tolerance and lung function, as measured by $\mathrm{FEV}_{1}$, remained unchanged.

$M$ ast cell chymase is known to be a potent stimulator of mucus secreting glands in vitro. ${ }^{23}{ }^{24} \mathrm{M}$ ast cells which accumulate close to mucous glands are positive for interleukin $6,{ }^{25} \mathrm{a}$ potent inducer of both mucous glycoprotein secretion and MUC2 gene expression in human bronchial organ explant cultures and bronchial epithelial cells. ${ }^{26}$

Vestbo and colleagues ${ }^{27}$ have reported a positive association between increased production of sputum and decline in lung function in a group of subjects with COPD; this decline was accelerated when compared with a group of COPD subjects without sputum production. Mucus hypersecretion is associated with increased risk of hospitalisation, morbidity and mortality, particularly in the later stages of COPD. ${ }^{28}$ The reduction in mast cell numbers, whose granular content may stimulate mucous secretion, could therefore be one mechanism to explain the beneficial effects of ICS on lung function observed during the first 3-6 months of the long term trials of ICS in COPD. ${ }^{11} 12$

In contrast to the effect on mast cells, our study showed that treatment with FP increased the number of mucosal neutrophils. Relatively high numbers of neutrophils have also been reported in bronchial biopsy specimens from severe asthmatics treated with high doses of inhaled or oral steroids. ${ }^{29}$ The presence of tissue neutrophils is the result of a balance between neutrophil recruitment and clearance/ longevity. Steroids decrease neutrophil apoptosis in vitro and thus promote neutrophil survival. ${ }^{30}{ }^{31}$ While the TEM technique allowed us to identify and quantify the numbers of apoptotic cells, such cells were present too infrequently for conclusions to be drawn as to the effects of ICS. M oreover, the functional significance of the potential for steroids to reduce the clearance of neutrophils by their effect on apoptosis is unclear in vivo and requires further study.

Based on the lack of effect on sputum eosinophils, it has been argued that ICS are ineffective as anti-inflammatory agents in COPD. ${ }^{32}$ However, a preliminary report has been published of a reduction in biopsy eosinophils following treatment with ICS in patients with COPD who were hyperresponsive to histamine, indicating an asthmatic component. ${ }^{33}$ Interestingly, one of our COPD patients had evidence of airway reversibility as he responded positively to a course of oral prednisolone; this patient had a relatively high baseline biopsy eosinophilia that was significantly reduced by ICS. We suggest that the lack of effect of ICS on eosinophils in COPD is due to the relatively low frequency of eosinophils at baseline, as evidenced in both the study by Keatings et $\mathrm{al}^{32}$ and our study, indicating that the signal is too small to show a treatment related effect.

In conclusion, our results show that ICS have selected antiinflammatory effects in COPD, as evidenced by the reduction in airway tissue mast cells. Our results offer one possible explanation for the short term improvement in lung function following ICS given to patients with COPD. ${ }^{12}$ The hypothesised relationships between mast cells, mucus hypersecretion, and $\mathrm{FEV}_{1}$ require further investigation. It is clear that additional treatments still need to be found to target the key cells thought to be responsible for the progressive decline of lung function in patients with COPD.

\section{ACKNOWLEDGEMENTS}

The authors gratefully acknowledge the contributions made by Glaxo-SmithKline and Lung Pathology Discretionary Funds and thank M r Andrew Rogers for technical assistance and advice.

\section{Authors' affiliations}

M J Gizycki, K L Hattotuwa, P K J effery, Lung Pathology Unit, Imperial College School of M edicine at the Royal Brompton Hospital, London, UK K L Hattotuwa, N Barnes, London Chest Hospital, London, UK

\section{REFERENCES}

1 COPD Guidelines Group of the Standards of Care Committee of the British Thoracic Society. BTS guidelines for the management of chronic obstructive pulmonary disease. Thorax 1997;52(Suppl 5):S1-28.

2 Siafakas NM, Vermeire P, Pride N B, et al. O ptimal assessment and management of chronic obstructive pulmonary disease (COPD). Eur Respir J 1995;8:1398-420.

3 Pauwels R, Anthonisen N, Barnes PJ, et al. G lobal initiative for chronic obstructive lung disease. $\mathrm{N}$ ational Institutes of $\mathrm{Health}$; $\mathrm{N}$ ational Heart, Lung, and Blood Institute, 2001: 1-30.

4 Jeffery PK. Remodeling in asthma and chronic obstructive lung disease. Am J Respir Crit Care Med 2001;164:S28-38.

5 O'Shaughnessy TC, A nsari TW, Barnes N C, et al. Inflammation in bronchial biopsies of subjects with chronic bronchitis: inverse relationship of CD8 + T lymphocytes with FEV1. A m J Respir Crit Care M ed $1997 ; 155: 852-7$

6 Lams BE, Sousa AR, Rees PJ, et al. Subepthelial immunopathology of large airways in smokers with and without chronic obstructive pulmonary disease. Eur Respir J 2000;15:512-6. 
7 Saetta M, Di Stefano A, Turato G, et al. CD8 + T-lymphocytes in peripheral airways of smokers with chronic obstructive pulmonary disease. Am J Respir Crit Care Med 1998;157:822-6

8 Saetta M, Baraldo S, Corbino L, et al. CD8 + cells in the lungs of smokers with chronic obstructive pulmonary disease. Am J Respir Crit Care Med 1999;160:711-7.

9 Lamb D, Lumsden A. Intra epithelial mast cells in human airway epithelium: evidence for smoking-induced changes in their frequency. Thorax 1982;37:334-42

10 Grashoff WF, Sont JK, Sterk PJ, et al. Chronic obstructive pulmonary disease: role of bronchiolar mast cells and macrophages. Am J Pathol 1997;151:1785-90

11 Pauwels RA, Lofdahl CG, Laitinen LA, et al. Long-term treatment with inhaled budesonide in persons with mild chronic obstructive pulmonary disease who continue smoking. European Respiratory Society Study on Chronic 0 bstructive Pulmonary Disease. $N$ Engl] Med 1999;340:1948-53

12 Burge PS, Calverley PM, Jones PW, et al. Randomised, double blind, placebo controlled study of fluticasone propionate in patients with moderate to severe chronic obstructive pulmonary disease: the ISO LDE trial. BMJ 2000;320:1297-303

13 Hattotuwa K, Gizycki M, Ansari A, et al. The effect of inhaled fluticasone on airway inflammation in CO PD: a double blind placebo-controlled study. Am J Respir Crit Care Med 2002;165:1592-6.

14 Jeffery PK, G odfrey RW A, A delroth $E$, et al. Effects of treatment on airway inflammation and thickening of reticular collagen in asthma: a quantitative light and electron microscopic study. Am Rev Respir Dis 1992;145:890-9.

15 Gizycki MJ, Adelroth E, Rogers AV, et al. M yofibroblast involvement in the allergen-induced late response in mild atopic asthma. Am J Respir Cell Mol Biol 1997;16:664-73.

16 Erjefalt JS, Andersson M, G reiff L, et al. Cytolysis and piecemeal degranulation as distinct modes of activation of airway mucosa eosinophils. J Allergy Clin Immunol 1998;102:286-94

17 Paggiaro PL, Dahle R, Bakran I, et al. Multicentre randomised placebo-controlled trial of inhaled fluticasone propionate in patients with chronic obstructive pulmonary disease. International CO PD Study G roup. Lancet 1998;351:773-80, 1968 (erratum).

18 van Grunsven PM, Van Schayck CP, Derenne JP, et al. Long term effects of inhaled corticosteroids in chronic obstructive pulmonary disease: a meta-analysis. Thorax 1999;54:7-14.

19 Barnes PJ. Inhaled corticosteroids are not beneficial in chronic obstructive pulmonary disease. Am J Respir C rit Care Med $2000 ; 161: 342-4$.
20 Calverley PM. Inhaled corticosteroids are beneficial in chronic obstructive pulmonary disease. Am J Respir Crit Care Med 2000;161:341-2.

21 Jeffery PK. Lymphocytes, chronic bronchitis and chronic obstructive pulmonary disease. In: Chadwick D, Goode JA, eds. Chronic obstructive pulmonary disease: pathogenesis to treatment. Chichester: John W iley, 2001: 149-68

22 Pesci A, Rossi GA, Bertorelli $G$, et al. M ast cells in the airway lumen and bronchial mucosa of patients with chronic bronchitis. Am J Respir Crit Care Med 1994;149:1311-6.

23 Sommerhoff $\mathrm{CP}, \mathrm{C}$ aughey $\mathrm{CH}$, Finkbeiner W $\mathrm{E}$, et al. M ast cell chymase: a potent secretagogue for airway gland serous cells. J Immunol $1989 ; 142: 2450-6$

24 Nadel JA. Role of mast cell and neutrophil proteases in airway secretion. Am Rev Respir Dis 1991;144:S48-51.

25 Bradding P, Roberts JA, Britten KM, et al. Interleukin-4, -5, and -6 and tumor necrosis factor- $\alpha$ in normal and asthmatic airways: evidence for the human mast cell as a source of these cytokines. Am J Respir Cell Mol Biol $1994 ; 10: 471-80$

26 Levine SJ, Larivee $P$, Logun C, et al. IL-6 induces respiratory mucous glycoprotein secretion and MUC-2 gene expression by human airway epithelial cells. Am J Respir Crit Care Med 1994;149:A29.

27 Vestbo J, Prescott E, Lange P. Association of chronic mucus hypersecretion with FEV 1 decline and chronic obstructive pulmonary disease morbidity. Am I Respir Crit Care Med 1996:153:1530-5.

28 Lange $\mathrm{P}, \mathrm{N}$ yboe J, A ppleyard $\mathrm{M}$, et al. Relation of ventilatory impairment and of chronic mucus hypersecretion to mortality from obstructive lung disease and from all causes. Thorax 1990;45:579-85.

29 Wenzel SE, Szefler S], Leung DYM, et al. Bronchoscopic evaluation of severe asthma. Persistent inflammation associate with high dose glucocorticoids. Am J Respir Crit Care Med 1997;156:737-43.

30 Cox G. G lucocorticoid treatment inhibits apoptosis in human neutrophils. Separation of survival and activation outcomes. J Immunol $1995 ; 154: 4719-25$

31 Meagher LC, Cousin JM, Seckl JR, et al. O pposing effects of glucocorticoids on the rate of apoptosis in neutrophilic and eosinophilic granulocytes. J Immunol 1996;156:4422-8.

32 Keatings VM, Jatakanon A, W orsdell YM, et al. Effects of inhaled steroids and oral glucocorticoids on inflammatory indices in asthma and CO PD. Am J Respir Cell Mol Biol 1997:155:542-8.

33 Verhoeven GT, Hegmans JP, M ulder PG, et al. Effect of an inhaled glucocorticosteroid, fluticasone propionate (FP), on inflammation in bronchial biopsies of CO PD patients with bronchial hyperresponsiveness. Am J Respir Crit Care Med 1999;159:A524. 